\title{
Correction: Energy-dependent nucleolar localization of p53 in vitro requires two discrete regions within the p53 carboxyl terminus
}

\author{
O Karni-Schmidt ${ }^{1} \cdot$ A Friedler $^{2,3} \cdot$ A Zupnick $^{1} \cdot \mathrm{K}^{\text {McKinney }}{ }^{1} \cdot$ M Mattia $^{1} \cdot$ R Beckerman $^{1} \cdot$ P Bouvet $^{4} \cdot$ M Sheetz $^{1}$. \\ A Fersht ${ }^{2} \cdot$ C Prives ${ }^{1}$
}

Published online: 1 August 2018

๑) Springer Nature Limited 2018

Correction to: Oncogene (2007) 26, 3878-3891; https:// doi.org/10.1038/sj.onc.1210162; published online: 22 Jan 2007
Following the publication of this article the authors noted that two images were duplicated in Figure 2B. The corrected figure $2 \mathrm{~B}$ is below. The authors wish to apologize for any inconvenience caused.

$\triangle$ C Prives

clp3@columbia.edu

1 Department of Biological Sciences, Columbia University, New York, USA

2 Department of MRC-CPE, Center for Protein Engineering, Medical Research Council, Cambridge, UK

3 Department of Organic Chemistry, The Hebrew University of Jerusalem, Givat Ram, Jerusalem, Israel

4 Laboratoire de Biologie Mole'culaire de la Cellule/UMR 5161, Ecole Normale Supérieure de Lyon 46, Alle'e d'Italie, 69364 Lyon Cedex, France 


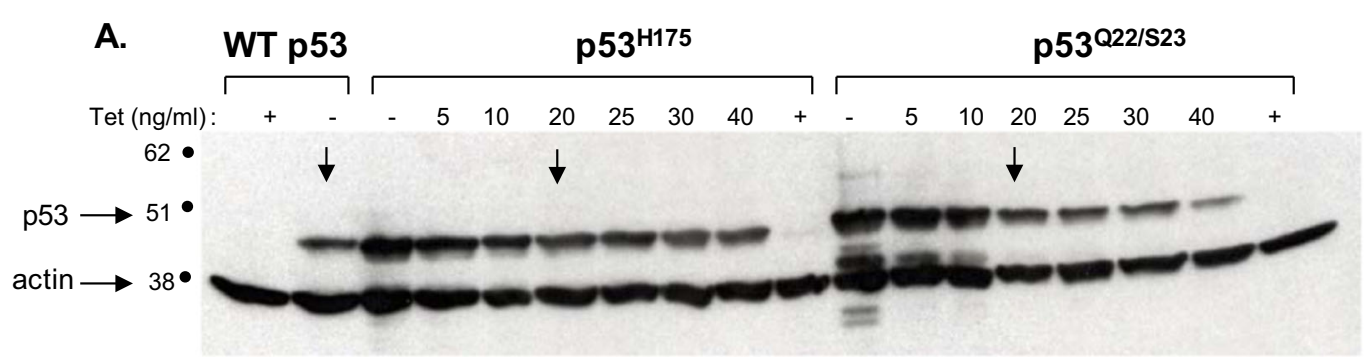

B. 1. WT $\mathrm{p} 53,0 \mathrm{ng} / \mathrm{ml}$ tet

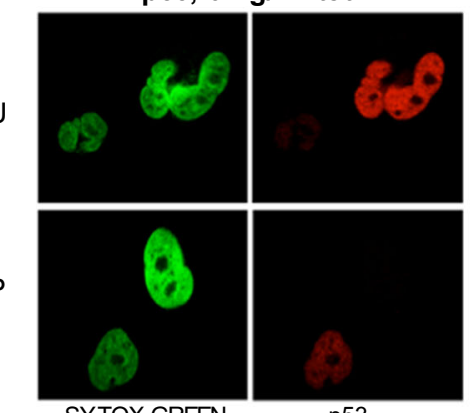

SYTOX GREEN
2. $\mathrm{p} 53^{\mathrm{H} 175}, 20 \mathrm{ng} / \mathrm{ml}$ tet
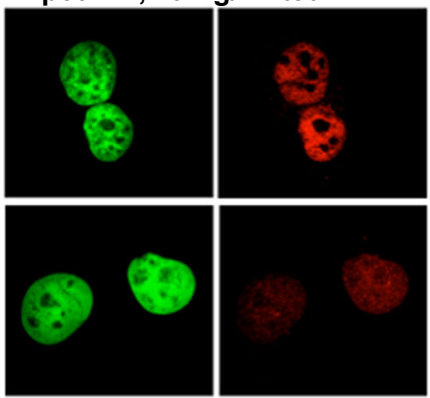

4. $\mathrm{p} 53^{\mathrm{H} 175}$, o $\mathrm{ng} / \mathrm{ml}$ tet
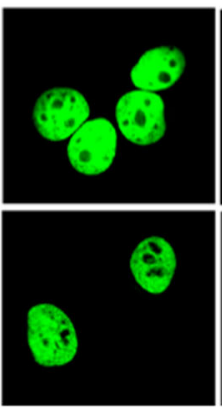

SYTOX GREEN
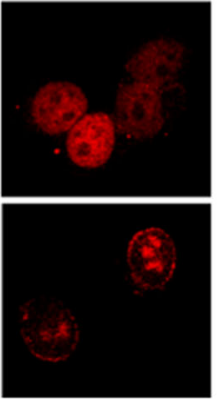

p53
3. $\mathrm{p} 53^{\mathrm{Q} 22 / \mathrm{S} 23}, 20 \mathrm{ng} / \mathrm{ml}$ tet

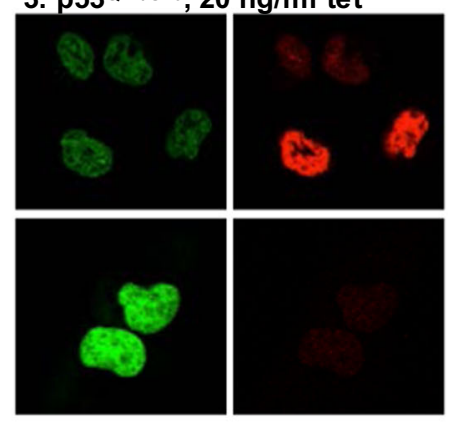

5. $\mathrm{p} 53^{\mathrm{Q} 22 / \mathrm{S} 23}, \mathrm{o} \mathrm{ng} / \mathrm{ml}$ tet

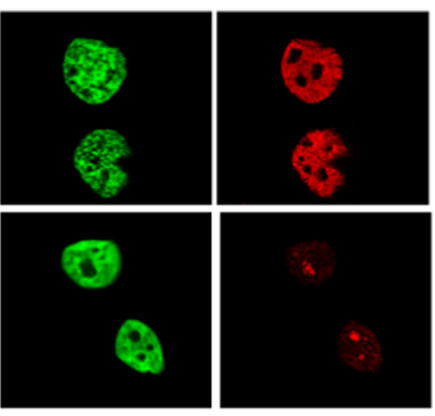

SYTOX GREEN

p53

Fig. $2 b$ 